\title{
Diet change of amphipods in the Hadal Trench revealed by fatty acid biomarker and stable isotope ratio
}

\author{
LINLIN SHI ${ }^{1}$, XI ZHANG ${ }^{1}$, WENJIE XIAO ${ }^{2}$ AND YUNPING \\ $\mathrm{XU}^{1}$ \\ ${ }^{1}$ Shanghai Ocean University \\ ${ }^{2}$ Southern University of Science and Technology \\ Presenting Author: linlinn_shi@qq.com
}

The hadal zone (from 6 to $11 \mathrm{~km}$ depth) is one of the least explored habitats on Earth, and the knowledge about trophic ecology of hadal organisms is limited. Here we analyzed fatty acids of the amphipods collected from three contrasting Pacific trenches that New Britain Trench (NBT; 8.2-8.9km), Mariana Trench (MT; $11 \mathrm{~km}$ ) and Massau Trench (MS; 6.9km). The predominance of $\mathrm{C}_{18: 1 \omega 9}$, high $\mathrm{C}_{18: 1 \omega 9} / \mathrm{C}_{18: 1 \omega 7}$ and high $\delta{ }^{15} \mathrm{~N}$ values suggested that hadal amphipods were necrophagous. The inter-trench comparisons based on $\mathrm{C}_{18: 1 \omega 9} / \mathrm{C}_{18: 1 \omega 7}, \mathrm{C}_{22: 6 \omega 3} / \mathrm{C}$

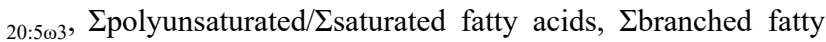
acids and principal component analysis (PCA) showed that the amphipods in the NBT were more dependent on high-quality organic matter (i.e., carrion), whereas those in the MT and MS more utilized detritus and bacterial organic matter as supplementary food. This inter-trench difference had been attributed to a bottom-up effect of food availability that the NBT has higher net primary productivity (NPP) and a strong terrestrial influence, whereas the MT and MS have lower NPP and insignificant terrestrial influences. We further explored the diet change of hadal amphipods in relation to ontogenetic development by analyzing the amphipod species (Alicella gigantean) collected in the NBT (8225 m depth). A total of 50 samples were divided into five developmental stages according to body length $(1-129 \mathrm{~cm})$ : Stages I (juvenile), II (sub-adult) and III/IV/V (adult). Mean total fatty acid content for stage I (237.7 \pm $105.6 \mathrm{mg} \mathrm{g}^{-1}$ ) was significantly lower than that for stages II to $\mathrm{V}$ (476.4 $\pm 49.0 \mathrm{mg} \mathrm{g}^{-1}$ ). The $\delta^{15} \mathrm{~N}$ of mussels (14.7-18.4\%o) positively correlated with the body length, whereas $\mathrm{C}_{20: 5 \omega 3} / \mathrm{C}_{22: 6 \omega 3}$ ratio negatively correlated with the body length. The PCA result revealed that stage I-individuals consumed more bacteria/zooplankton debris, stages II to IV-individuals primarily preyed on carrion, while stage $\mathrm{V}$-individuals had more diverse diet (benthic fauna/algae and carrion). Overall, fatty acid and stable isotope data suggested an ontogenetic diet shift for hadal amphipods that may contribute to their success in the deepest ocean. Some preliminary data on compound specific nitrogen isotopes of amino acids were also presented in order to estimate trophic levels of amphipods. 